\title{
CASTIGO Y JUSTICIA CÓSMICA EN LA TEORÍA PLOTINIANA DE LA PROVIDENCIA
}

\section{Patricio Domínguez Valdés Universidad de los Andes. Chile}

Resumen: El presente artículo explora un aspecto de la respuesta plotiniana ante el problema del mal en el tratado de la providencia (En. III, 2, 3 [47]), a saber, la cuestión del sufrimiento del virtuoso y la aparente impunidad del vicioso. Para ello, analiza dos doctrinas platónicas usadas por Plotino (Adrasteia en Fedro 248ss. y la lex talionis de Leyes IX, 872e) a la luz de la metáfora de la obra de teatro, a partir de la cual Plotino intenta hacernos comprensible el modo en que la providencia gobierna el universo con suma justicia.

Palabras clave: Plotino, providencia, Adrasteia, castigo, justicia.

\section{PUNISHMENT AND COSMIC JUSTICE IN PLOTINUS' THEORY OF PROVIDENCE}

\begin{abstract}
This article explores one aspect of the Plotinian answer to the problem of evil in his treatise on providence (En. III, 2,3 [47]), i.e. the question concerning the suffering of the virtuous and the apparent impunity of the vicious. To that end, it analyzes the Platonic doctrines used by Plotinus (Adrasteia in Phedrus $248 \mathrm{ff}$. and the lex talionis of Laws IX, 872e) in the light of the metaphor of the piece of theater, based on which Plotinus intends to make comprehensible the way the providence rules the universe with utmost justice.
\end{abstract}

Keywords: Plotinus, providence, Adrasteia, punishment, justice.

Recibido: 24.07.2017 - Aceptado: 28.09.2017

Correspondencia: Patricio Domínguez.

Email: jpdominguez@miuandes.cl

Licenciado en Filosofía, Universidad de los Andes, Chile. Doctor en Filosofía, Universidad de Tubinga, Alemania. Profesor adjunto al Instituto de Filosofía de la Universidad de Los Andes, Santiago de Chile. Mons. Álvaro del Portillo 12455, Las Condes, Santiago, Chile. Fono: (56-22) 6191336. 


\section{Introducción}

T a cuestión de si acaso la divinidad gobierna el mundo y hasta qué punto, esto es, la cuestión de la providencia ( $\pi \rho \operatorname{có}_{\mathrm{vol} \alpha}$ ), fue uno de los tópicos más controvertidos durante la antigüedad. Plotino, quien se cuenta entre los más tratadistas más destacados en la materia ${ }^{1}$, elabora su propia teoría de la providencia siguiendo a Platón y a su "teodicea" de Las Leyes, sosteniendo que el universo, incluso en sus detalles más ínfimos, es un todo ordenado y racional, gobernado por una divinidad buena y justa ${ }^{2}$. Esta postura fue objeto de varias críticas en la antigüedad, siendo unas de las más importantes 1) la objeción a partir del mal y 2) la objeción a partir del libre albedrío. La primera objeción sostiene que la existencia de mal y desorden en el mundo es una prueba o bien de que la providencia no existe sino limitadamente (cf. LS 13; Cicerón, nat. deor. $1,8,18 ; 20,54-56)$ o bien de que el mundo es ontológicamente malo (cf. Sexto Empírico, Pyr. III, 9-12)33 la segunda objeción sostiene que la doctrina de la providencia es incompatible con nuestra experiencia común de que el libre arbitrio y la responsabilidad sí existen (cf. una versión de este argumento en Cicerón, De Fato 10, $20 \mathrm{ff} ; 17,40)^{4}$.

Plotino considera, en general, que la existencia de la providencia en el mundo es un hecho "evidente" ( $\left.\delta \tilde{\eta} \lambda{ }^{\circ} v\right)$, comprensible a partir de la belleza, ordenamiento y concatenación de los diferentes seres que pueblan el universo (En. III, 2, 1, 4; En. III 2, 13)5. El cosmos completo, en su

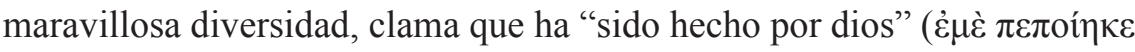

1 Cf. Beutler-Theiler (1956ss: 332); Sharples (1994: 171).

2 Para una visión sinóptica de la teología platónica de las Leyes, cf. Mayhew (2003). Los antecedentes estoicos de la doctrina plotiniana se pueden ver en SVF 2: $528,933,1118$.

3 Este el núcleo de la objeción gnóstica, tal como lo reconstruye Plotino en En. II, 9, 4, 22-32; II, 9, 9, 1-26 y que aparece como trasfondo en el En. III, 2-3.

4 Hay que notar que Plotino mismo está de acuerdo en que el orden del mundo entendido como un "destino" ( $\dot{i \mu \alpha \rho \mu \eta \nu \eta \nu) ~ o m n i a b a r c a n t e ~ c o n d u c e ~ a ~ t e s i s ~}$ deterministas inaceptables, como la vaciedad de sentido de la expresión "lo que

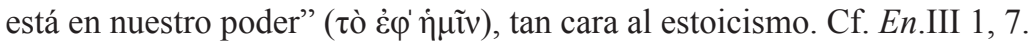

5 Cf. Cicerón, De natura deorum 2, 4: quid enim potest ese tam apertum tamque perspicuum, caelum suspeximus caelestiaque contemplatisumus, quam ese aliquid numen praestantissimaementis, quae haec regantur. 


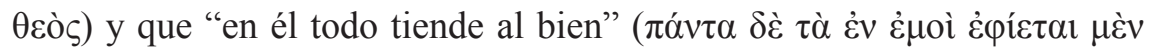

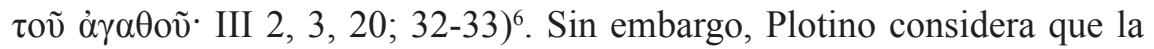
existencia del desorden y del mal en el mundo plantea una objeción nada despreciable a la doctrina de la providencia. En efecto, ¿cómo podemos afirmar que el mundo está regido por una divinidad sumamente justa y bondadosa y al mismo tiempo reconocer que en el cosmos no todo es perfecto, sino que por el contrario, existe el mal físico y moral? En ese sentido, la aseveración de que el cosmos es gobernado por una divinidad justa parece contradecir el hecho de que a menudo los buenos reciben males y los malos reciben bienes (En. III, 2, 6.). El hecho de que los buenos reciban males no constituye, con todo, una objeción de peso para Plotino, pues, remontándose a una tesis de origen socrático, no cree que los llamados

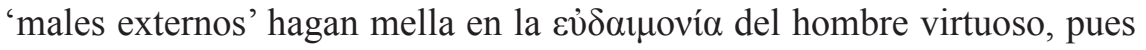
para él no "no hay nada malo"7. No obstante, Plotino reconoce que el hecho de que el bueno sufra injusticia y el malo prospere en esta vida (por ejemplo, de que los malvados esclavicen a los buenos y que éstos sufran crímenes a manos de los primeros) ${ }^{8}$ ciertamente no es un estado de cosas prima facie "proporcional", "apropiado" o "según el mérito" (

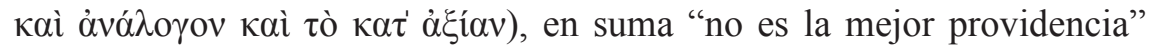

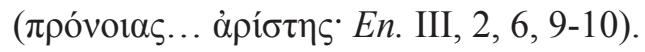

Para enfrentar esta aporía, Plotino formula un discurso muy sofisticado cuyo fin es convencer al lector de que, en realidad, los males que experimentamos "aquí abajo", por muy horribles que nos puedan

$6 \mathrm{Si}$ bien es cierto que en el tratado de la providencia de Plotino no encontramos una demostración pormenorizada de la existencia de la providencia antes de la investigación de su esencia, como se podría esperar de un esquema de investigación que se remonta a Aristóteles (Cf. Analytica Posteriora II 1, 98b) después asumido por la retórica (cf. Cicerón, De oratore 14, 45), con todo, podríamos reconstruir una prueba de la misma de tipo platónica (i.e. a partir de la graduación en el universo) atendiendo a la perfección ("la maravillosa artesanía") del cosmos, desde el movimiento celeste a la prodigiosa complejidad de los animales y plantas más ínfimos. Cf. En. III 2, 13.

7 Cf. En. III, 2, 6, 3; cf. también I, 4, 13 y II, 9, 9 1-5.Para la tesis de que el virtuoso es inmune al mal se Cf. Platón, Apol. 41d1.

8 Cf. Boecio, De Consolatione Philosophiae. IV prosa 6. Para un panorama crítico del problema de la teodicea en la historia de la filosofía, cf. Hermanni (2002). 


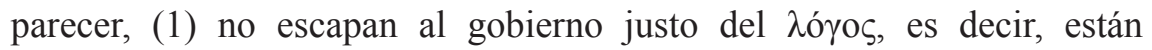
perfectamente integrados dentro de un cosmos bueno en su totalidad, y (2) que las calamidades de esta vida (por ejemplo las guerras) no son en realidad algo terrible, sino meros "juegos infantiles" carentes de seriedad que sólo afectan al "hombre exterior" (En. III, 2, 15, 35ss.).

En este artículo me centraré en la idea (1), es decir, intentaré explicar cómo concibe Plotino la justicia del gobierno de la providencia. Más específicamente, exploraré la conexión que hace explícitamente Plotino esta idea de justicia con el mito de Adrasteia del diálogo platónico Fedro (248c ss.) y con la metáfora del teatro aplicada a la vida humana en relación al gobierno divino. Como veremos, esta metáfora le viene como anillo al dedo Plotino para su concepción de la providencia según el mito de Adrasteia, por cuanto en ella se nos manifiesta intuitivamente la existencia de un todo bueno que contiene males justamente gobernados y juzgados por su autor. Dividiré este artículo en dos partes. En la primera expondré la versión plotiniana de la ley del talión con recurso a dicho mito y en la segunda expondré la metáfora del teatro en relación a la justicia providencial, seguida por una breve conclusión.

\section{Lex talionis}

Para ilustrar la "caída" del alma desde su estado original de visión de la Idea hasta este estado fáctico de ignorancia, Platón propone el siguiente mito en el Fedro: las almas moran junto a los dioses en un ámbito plenamente inteligible, formando un séquito de carros alados que da vueltas concéntricas a esta región, que Platón llama "la llanura de la verdad" $\left(248 \mathrm{~b}^{9}\right)$. Las mejores de las almas giran fijando la vista en esta región, mientras que otras alcanzan a vislumbrarlo sólo de tanto en tanto. Finalmente, una clase de almas no alcanza a vislumbrar este ámbito de la

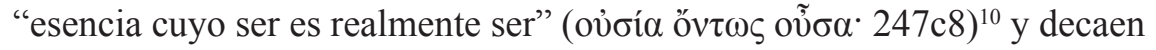
al mundo de la mera opinión. Ahora bien, a cada alma le espera un destino diferente, de acuerdo al grado visión que ha tenido de la "pradera de la verdad" en su giro. Si un alma efectivamente alcanza a ver éste ámbito queda indemne hasta el próximo giro, pero el alma que no ha podido vislumbrarlo, como dijimos, pierde las alas y cae a tierra (248c8). El destino o "parte" que le es asignada a cada alma según su grado de mayor a

9 Cf. En. VI, 7, 13.

10 Sigo la traducción de este giro platónico de E. Lledó (1986). 
menor visión, dice Platón, corresponde al "precepto de Adrasteia" $(\theta \varepsilon \sigma \mu$ ó A $\delta \rho \alpha \sigma \tau \varepsilon i ́ \alpha \varsigma)$. Según este precepto, es ley (vó $\mu \varsigma$ ) que quien caiga a tierra por no haber contemplado la verdad, se implante en diferentes cuerpos: desde el cuerpo de un filósofo (la mejor parte posible) hasta el cuerpo de un tirano (la peor parte posible), pasando por otros siete estados intermedios (248d-248e). En ciertos casos puede ocurrir incluso que el alma de un hombre pase a vivir en un animal y viceversa (249b).

En el nombre de A $\delta \rho \alpha ́ \sigma \tau \varepsilon \imath \alpha$ concurren varias asociaciones ${ }^{11}$. De origen probablemente no griego, el nombre de esta diosa venerada en Asia Menor fue relacionado etimológicamente por los griegos con el verbo $\delta 1 \delta \rho \alpha ́ \sigma \kappa \omega$ (huir). Adrasteia significaría literalmente: "irrehuible", "inescapable". En cuanto tal fue considerada como la personificación de la necesidad del destino ${ }^{12}$. En el culto se le asoció también a Némesis, la diosa del castigo justo o de la venganza ${ }^{13}$. La idea que subyace a la conexión (o incluso identificación) entre Adrasteia y Némesis es que el castigo por una mala acción es irrehuible, inevitable.

Pues bien, Plotino retoma esta asociación para explicar de qué modo la providencia gobierna con justicia el cosmos "desde principio a

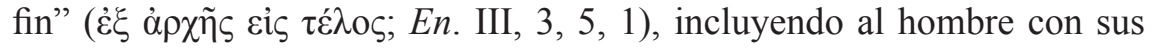
acciones libres. Según nuestro filósofo, la providencia es $\alpha \delta \rho \alpha ́ \sigma \tau \varepsilon 1 \alpha$, vale decir, "nada puede escapar jamás a la ley del todo" (En. II, 2, 4, 25-26) Esto significa en la práctica que la providencia no deja jamás impune una mala acción, sino que siempre ésta resulta vengada y castigada. Platón ya había expresado esta idea en Las Leyes, formulando dramáticamente la idea de omnisciencia divina: "En efecto, esa justicia nunca te descuidará, ni aunque siendo tan pequeño te hundieras en la profundidad de la tierra, ni si, enalteciéndote, volaras al cielo, sino que pagarás el castigo correspondiéndote por sus acciones, o bien cuando estés aquí, después de marchar al Hades, o tras desplazarte a un lugar todavía más execrable que ésos" (Leyes X, 905a1-905b2. Trad. Francisco Lisi).

Volvamos al punto de partida de la objeción a partir del mal: el sufrimiento del hombre virtuoso y la prosperidad del malvado. Como

11 Cf. Graf (1996) en Die Neue Pauly, I, p. 130; Yunis (2011: 143).

12 Cf. DK I B13; Esquilo, Prom. 936.

13 Cf. Aristóteles, De mundo 401b13s.

14 Cf. Platón, Leyes X, 903b5-10. 
dijimos anteriormente, el que le vaya mal al hombre bueno, esto es, que sufra enfermedades, desgracias y pérdidas, podría inclinarnos a pensar que la providencia lo ha abandonado a su propia suerte y que ésta en realidad no se inmiscuye en los asuntos humanos. Por otra parte, muchas veces sucede que un hombre vicioso y violento vive una vida aparentemente próspera y absolutamente impune, lo cual nos confirma en la sospecha de que la providencia en realidad no hace justicia cabal y que su castigo es evitable ${ }^{15}$. Sin embargo, Plotino desecha esta objeción no atacándola directamente, sino abordándola desde principios de orden superior que reinterpretan dicha vivencia:

"Tampoco hay que desechar el argumento aquel que dice que la Razón, en cada caso, no mira al presente, sino a los ciclos pasados y también al futuro, de modo que, basándose en ello, pueda graduar la valía de cada cual e invertir su suerte [ $\mu \varepsilon \tau \alpha \tau \imath \theta \varepsilon ́ v \alpha 1]$ convirtiendo en esclavos a los amos de antaño, si fueron malos amos y porque eso es lo que les conviene, y en pobres a los ricos, si usaron mal de sus riquezas [...] y haciendo que los que asesinaron injustamente sean a su vez asesinados, injustamente por parte del asesino, pero justamente para la víctima misma,

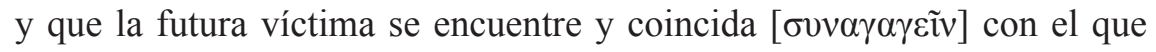
está dispuesta a perpetrar lo que aquella estaba destinada a padecer" (En. III 2, 13,1-11, Trad. Igal)

A partir de este texto podemos extraer, para nuestra exposición, dos ideas capitales. En primer lugar, la importancia sistemática que tiene idea de reencarnación para la teoría plotiniana de la providencia ${ }^{16}$. En efecto, la reencarnación es la conditio sine qua non para que, basándose en la retención y anticipación de los sucesos situados en el tiempo y en la valoración de los mismos, el $\lambda$ ó $o \zeta$ sea capaz de re-situar al agente moral (en este caso, al vicioso) en una situación perfectamente contraria. En segundo lugar, la doble cualificación del acto moralmente reprochable del vicioso (por ejemplo, el asesinato). Según esta doble cualificación, un acto malo como el asesinato es injusto desde el punto de vista de la intención del agente, pero justo desde el punto de vista del castigo del paciente ( $\tau \tilde{\omega}$ $\pi \alpha \theta$ óv $\tau$ ). Esta distinción es importante a la hora de explicar cómo un acto injusto en sí mismo puede ser justo considerado desde una perspectiva

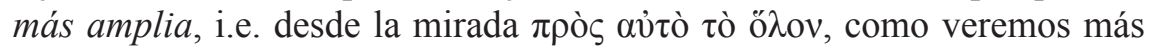

15 Cf. Gorgias 470 d ss.

16 Rich (1957: 235-237). 
adelante.

Estas dos ideas pueden rastrearse, al menos en sus aspectos fundamentales, en Platón ${ }^{17}$. En numerosos diálogos platónicos aparece la idea, presente por lo demás en diferentes estratos de la cultura griega y de otras culturas antiguas, de que después de la muerte el alma es juzgada de acuerdo a sus acciones y conforme a eso castigada o premiada en un estado post-mortem (sea en una vida terrena, sea en otro ámbito ${ }^{18}$. Plotino usa, además del citado pasaje del Fedro, un importante pasaje de Las Leyes (IX, 872e). En él Platón expone una doctrina "revelada por los antiguos

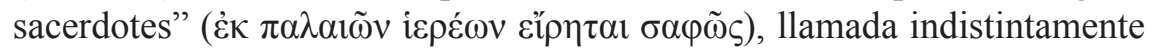
$\mu \tilde{v} \theta$ os o $\lambda$ ó $\gamma \circ \varsigma$, que decreta que todo crimen ha de ser pagado con la misma moneda, de suerte que el homicida se reencarne en un asesinado y el violador en una muchacha violada. Esta tesis de la ineludible justicia, "puesta por los dioses por sobre toda justicia" (Leyes X, 905a2-3) reaparece en el tratado plotiniano de la providencia, pero ahora con un acento aún más inquietante: no sólo se dice que todo crimen será castigado con la ley del talión en una vida futura, sino que este principio vale también retrospectivamente: todo crimen que experimentamos en el presente no es más que el justo castigo ( $\delta i ́ \kappa \eta)$ de un crimen cometido en una vida anterior. Si todo lo que sucede en el mundo sucede de acuerdo al $\lambda$ ó $\gamma o \varsigma$ justo de la providencia, entonces los sufrimientos que nos dejan tan perplejos porque prima facie nos parecen injustos, en realidad son justos castigos de crímenes pretéritos: "Pues no es verdad que uno sea esclavo por una coincidencia, ni que sea ultrajado en su

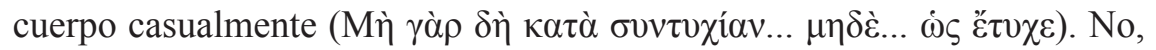
sino que fue autor otrora de lo mismo de que es víctima ahora, y así, si uno dio muerte a su madre, morirá, hecho mujer, a manos de su hijo, y si violó a una mujer, será mujer para que sea violada. De ahí viene, por revelación divina, el nombre de Adrasteia. Porque esta disposición ordenada ( $\delta i \alpha ́ \tau \alpha \xi ı)$ ) del cosmos es realmente "Adrasteia" (= "irrehuible"), realmente justicia ( $\Delta$ íkๆ) y sabiduría maravillosa" (En. III, 2, 13; 11-18. Trad. J. Igal).

Siguiendo con este esquema, no nos queda sino decir que el pobre fue un mal rico en su vida pasada, y que el esclavo fue un mal amo (En.

17 Para el argumento acerca de la justicia del castigo, cf. Gorgias $476^{\mathrm{a}}$ ss.

18 Cf. Gorgias 523a-527a; Fedón 107d-114c; Fedro 246-249d; República X, 614b-612b; Timeo 41e-42c; 90e-92c; Menón 81a-d; Leyes 870d-e; 872e; 903b-905d. Para una visión panorámica de la doctrina de la metempsicosis cf. Müller (2009). 
III 2, 13, 5-6). Ningún mal ni ninguna desgracia, por consiguiente, ocurren fortuita o azarosamente. Detrás de alguna calamidad, sostiene Plotino, siempre está la acción del $\lambda$ ó $\gamma$ os justiciero de la providencia, que gobierna el universo de las acciones malas del hombre coordinándolas, de modo tal que el mal que se hace siempre recaiga en alguien culpable del mismo crimen. Dicho en otras palabras: la providencia dispone que el mal de pena sea siempre la exacta contraparte del mal de culpa. De este modo, la maldad moral de un agente concreto queda redireccionada hacia un bien, a saber, el castigo de un culpable. El homicida o el violador, aunque estén actuando objetivamente mal y contradiciendo con ello la disposición óptima de las cosas, no con ello se sustraen a la justicia: por un lado actúan, aun sin quererlo, como agentes de justicia retributiva, y por otro, sus acciones quedan por así decirlo juzgadas y "grabadas" inevitablemente en la memoria del $\lambda o ́ \gamma o s$, de suerte que éste pueda disponer un determinado

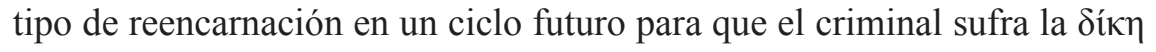
que le corresponda.

Con todo, uno podría objetar: ¿qué tipo de castigo tienen las acciones malas que no atropellan al otro, sino que se cometen "contra uno mismo", como las acciones intemperantes? Si la providencia castiga las acciones viciosas disponiendo que el alma se reencarne en una víctima de dicha acción, ¿en qué se reencarnará por ejemplo el borracho o el glotón? En efecto, la tradición filosófica platónica identifica como $\alpha \mu \alpha \rho \tau i ́ \alpha$ no sólo aquellas acciones reprochables por implicar una violación del orden de la justicia para con los demás hombres, sino también para con la jerarquía entre cuerpo y alma. ¿Qué castigo post-mortem tiene el vicioso que vive

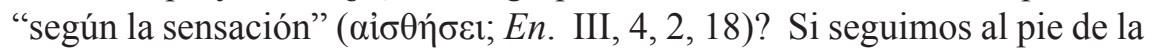
letra la ley del talión extraída de Leyes IX, 872e parece que no obtenemos una respuesta satisfactoria. Como el borracho es a la vez agente y paciente de su propio actuar, obviamente no existe la posibilidad de que se reencarne en un paciente que sea distinto del agente: el borracho terminaría reencarnándose en un borracho - lo cual no constituye un castigo desde el punto de vista del castigado. Sin embargo, al igual que Platón, Plotino tiene en mente la posibilidad de otro tipo de reencarnación, a saber, el paso a otra especie de ser vivo ${ }^{19}$. En efecto, para aquellos hombres que han vivido su

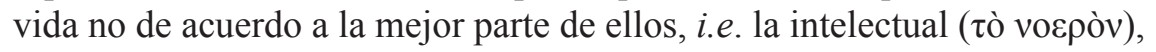
sino las peores, a saber, la sensitiva y la vegetativa, Plotino establece un

19 Cf. Fedón 81b; República X, 620; Timeo 91-92. 
sistema de reencarnación en diferentes especies de animales, según el amor sensible desordenado que predominó en ellos durante su vida humana (En. III, 4, 2) $)^{20}$.

Sin embargo, no debemos engañarnos a partir del lenguaje usado para describir la acción justiciera de la providencia. En efecto, la adscripción de actividades a la providencia (por ej. En. III, 2, 4-5) podría hacernos pensar que ella es, en cierto modo, causa activa del mal. Haciendo frente a esta posible objeción, Plotino señala que el logos no causa en sentido estricto los males, sino que usa los males inevitables ${ }^{21}$ y los re-ordena bajo sí para extraer de ellos consecuencias positivas, por ejemplo, cuando a partir de la corrupción de un cuerpo se genera otro, o cuando la pobreza y la enfermedad sirven al hombre para progresar en la virtud. A partir de esta explicación, los males del mundo parecen caer bajo el gobierno de la providencia universal a modo de permisión, es decir, el $\lambda$ ó $o \varsigma$ no actúa como factor activo en la producción del sufrimiento, sino que meramente lo permite sin por ello dejar de gobernarlo (i.e. lo usa como "útil en vistas

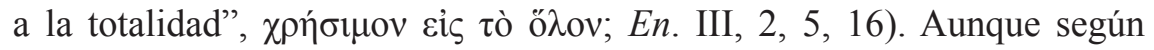
el lenguaje usado el $\lambda$ ó ${ }_{0} \varsigma$ parece actuar positiva y activamente como productor del sufrimiento, haciendo justicia "hasta el último rincón" 22 del

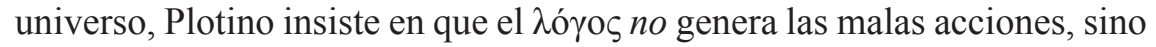
que "las lleva consigo" (En. III, 3, 1, 4) y que éstas "son engarzadas en el conjunto de la providencia" (En. III, 3, 5, 27). En efecto, es consistente con el platonismo el exculpar a la divinidad de toda mala acción a partir del principio "el bien sólo puede engendrar bien" y sostener que la causa

20 Otros textos importantes relativos a la reencarnación el corpus plotiniano se encuentran en En. III, 3, 4, 33-44; IV, 3, 27; IV, 7, 8; IV, 7, 14 VI, 7, 6. Como mostró Rich (1957: 233ss.), el hecho de que sea difícil encontrar coherencia en la doctrina de la reencarnación no implica que ésta sea para Plotino un mero dato de la herencia platónica; por el contrario, el hecho de que Plotino se tomara tantas molestias en responder a las objeciones que impugnaban la coherencia de la reencarnación con otras doctrinas de su sistema demuestra suficientemente que la reencarnación es una asunción genuinamente plotiniana.

21 Cf. Teeteto 176a5. Para explicar el "uso" que le da la providencia a los males Plotino acude a la metáfora de la cicatrización de una herida por parte del animal; cf. En. III 3, 5, 29ss.

22 Para esta expresión cf. Fedón 107d, República X 620d-e; Político 271d-e; 272e-273a. 
del mal es el hombre mismo (En. III 3, 5, 34-35) ${ }^{23}$. Dicho en términos del mito de Adrasteia: la divinidad gobierna la totalidad de las cosas de modo que el mal sea castigado de modo inexorable, pero no castigando ella misma directamente, sino disponiendo que el mal que el mismo hombre causa quede subsumido en una economía global de castigos fundada en la reencarnación. Sin la reencarnación, por ende, no sería posible hablar de una providencia justa.

Otro posible problema de esta teoría consiste en ciertas consecuencias del principio de Adrasteia: si todos los sufrimientos de este mundo son la expresión de la justicia cósmica, entonces siempre hay una injusticia (humana) precedente. Esto nos llevaría a la siguiente disyuntiva: o bien tenemos un comienzo absoluto de injusticias (algo así como un peccatum originale) o tenemos una cadena infinita de injusticias y castigos. Si optamos por el primer cuerno de la disyunción, tendríamos que aceptar que el principio plotiniano de que el sufrimiento no es azaroso vale sólo para los castigos posteriores a este primera injusticia. Pero si esto es así, ¿qué justicia rige para quien sufre la injusticia en primer lugar, si no está pagando por ningún crimen pretérito? Si optamos por el segundo cuerno del dilema, tendríamos que aceptar que no hay un comienzo absoluto en la cadena de males y castigos, sino que este gran drama "exterior", con sus

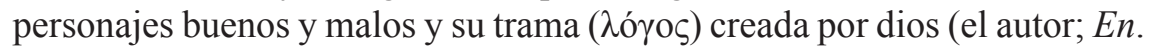
III, 2, 17) es un eterno devenir de "crímenes y castigos". Todo indica que Plotino optaría por la segunda alternativa. Y es que el cosmos, tal como él lo concibe, no es 'providencial' en el sentido de que sea el producto de una deliberación e intención temporalmente anterior de dios (pues tal es

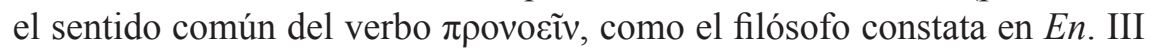
$2,1,12-14$ ), sino que la anterioridad a la que refiere el término (a saber, mediante el prefijo pro), como bien señala Kalligas, mienta una prioridad ontológica $^{24}$. El mundo no es, además, un ente temporal, sino que existe $a b$ aeterno (cf. En. V, 8, 7) $)^{25}$.

23 Platón, República II 379c.

24 Kalligas (2014: 447).

25 Es de notar que, aunque Platón en Timeo 29d-30b describe al mundo como

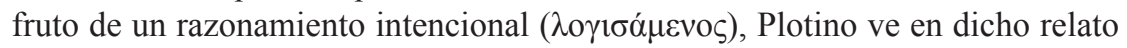
sólo una representación mítica y no una doctrina metafísica. Para un análisis de los argumentos en contra de lecturas literales del Timeo con respecto a la (no) eternidad del mundo, cf. Tonelli (2012). 
Sin embargo, existe una segunda causa aún más profunda para afirmar la existencia de la "inescapable justicia": el mal en general, y el mal específico causado por el hombre, son en cierta manera necesarios. Dado que el mundo no es el bien en sí, sino que es bueno relativamente y por participación, es inevitable que en él se dé la "insuficiencia de bien" ( $\alpha \gamma \alpha \theta$ oṽ ... हैं $\lambda \lambda \varepsilon i \psi v i v ; E n$. III, 2, 5, 28). Desear la inexistencia de los males en este mundo "aquí abajo" es no entender la constitución imperfecta y participada del mismo, es decir, es desear que el mundo no sea mundo,

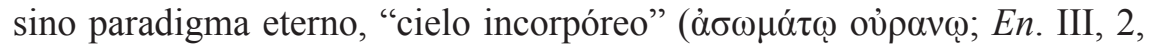
$4,7)$, y, a fin de cuentas, desear abolir la providencia (En. II, 3, 7, 5-7). Haciendo eco de Teeteto 175a5, Plotino sostiene que "los males no pueden desaparecer" (En. III, 2, 5, 29; III, 2, 15, 11, et passim). La necesidad del mal es ciertamente una tesis cuya fundamentación es en último término metafísica, vale decir, tiene que ver con la dependencia del mundo material del Uno a través de una serie de mediaciones o degradaciones (cf. En. I, 8; II, 4) ${ }^{26}$. Sin embargo, en el tratado de la providencia podemos encontrar otro tipo de "explicación" para hacer comprensible esta tesis, que no hace uso de dichas teorías metafísicas. Se trata de una serie de metáforas a las que hicimos alusión al principio de este artículo, las cuales, según Plotino, deberían ayudarnos a comprender que el mal que sufrimos "aquí abajo" pertenecen necesariamente a la estructura de un cosmos bueno. La importancia de este segundo tipo de explicaciones se revela especialmente interesante toda vez que fueron ellas las que más influencia histórica tuvieron en la configuración de la metafísica occidental a través de la patrística $^{27}$.

\section{EI teatro como metáfora de la justicia providencial}

Cuando Agustín de Hipona, en uno de sus tantos pasajes que acusan una marcada influencia neoplatónica, señala que nuestra dificultad para comprender el orden providencial del universo en su conjunto se debe a que estamos "entretejidos en él como partículas" (intexti universum, cui

26 Para el estado de cuestión hasta el siglo pasado sobre el difícil tópico del origen del mal en Plotino cf. Schaefer (2000: 3-7).

27 Cf. por ejemplo, San Agustín De ordine I 2; De civitate dei XI, 18; PseudoDionisio, De divinis nominibus IV, 31ss. 
particulae... $)^{28}$, de modo explícito está acudiendo a una símil tomado del mundo del arte (en este caso, el tejido, el textus). Las metáforas tomadas del ámbito estético-artístico le sirven al Hiponense para hacer más comprensible la idea de que la belleza del universo implica partes feas, o lo que es lo mismo, que la bondad del universo implica ingredientes malvados. En efecto, un tejido es una unidad conformada por muchos elementos y colores, todos ellos disímiles entre sí y algunos quizá aisladamente feos, pero de cuya unidad orgánica resulta un todo bello. Siguiendo a Plotino, Agustín señala que la tarea de quien quiere comprender el sentido del mal se parece a la visión global de un mosaico opuesta a la visión particular de sus teselas ${ }^{29}$. En este mismo tenor, Plotino había señalado que quien se queja y se lamenta del orden existente en el universo es como el lego en pintura que le echa en cara al pintor que no todos los colores son bellos, cuando en realidad lo importante es el resultado total, en donde "cada parte tiene su color apropiado" (En. III 2, 11, 9-12). En efecto, es en Plotino en donde encontramos con mayor profusión el uso de metáforas estéticas para explicar el papel del mal en el mundo. Su tratado de la providencia presenta múltiples ejemplos extraídos de la vida diaria de productos artísticos que conforman una unidad en sí misma bella y buena, pero que están compuestos de contrarios, entre los cuales se encuentran elementos feos o malos en sí mismos considerados. Tales ejemplos sonla melodía (En. III, 2, 3; 16; 17), la danza del pantomimo (III, 2, 17, 9-13) ${ }^{30}$, la siringa (III 2, 17, 70-75), y principalmente la obra de teatro (III, 2, 16-18) ${ }^{31}$.

¿Cómo funcionan estas metáforas? En general, todas ellas comparten la misma estructura. Se trata de presentar ante el lector productos artísticos bellos que él, sin mayor cuestionamiento, considera bien acabados. En seguida se desglosa la composición de estos y se cae en la cuenta de que entre sus elementos los hay de opuesta clase y valor: oscuros y claros (en el caso de las artes pictóricas) agudos y graves (las notas de la siringa) bellos

28 De civitate Dei XII, 4. Para un estudio de la influencia de Plotino en Agustín cf. Parma (1971).

\section{De ordine, I, 2.}

30 Cf. la explicación sobre el pantomimo de Beutler-Theiler (1956: 355-356).

31 La lista de productos no artísticos que sirven para la metáfora incluye también a la guerra (En. III, 3, 2), el animal (En. III, 2, 8) y la ciudad (En. III, 2, 11; cf. también II 9, 9). 
y feos (en el caso de la música), buenos y malvados (el caso de la danza del pantomimo y la obra de teatro). A partir de esta constatación, se cae en la cuenta de que la bondad "total" del producto artístico no es causada por una composición de elementos óptimos en sí mismos, sino por una composición de elementos viles y nobles; de suerte que la bondad del todo resulta comprensible a partir de una perspectiva "holística":

"Sería una inculpación bien absurda la de quien, basándose en las partes, inculpara al conjunto. Hay que considerar las partes en su relación

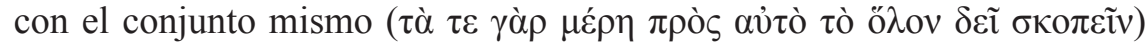
si están en consonancia y armonía con él, y, al considerar el conjunto, no hay que fijarse en ciertas partes insignificantes" (En. III, 2, 3, 12-14, trad. Igal $)^{32}$.

La metáfora de la obra de teatro ${ }^{33}$ es probablemente la metáfora más útil a la hora de representar la doctrina plotiniana de la justificación del mal y la justicia providencial, pues en ella aparece no sólo aquel aspecto "estético" del mal analogable a la melodía o al mosaico, sino que aparece el hombre como sujeto libre de buenas y malas acciones custodiado por un autor que lo premia o lo castiga ${ }^{34}$. Echando mano al paralelismo entre los campos semánticos de la creación teatral y el gobierno divino (el

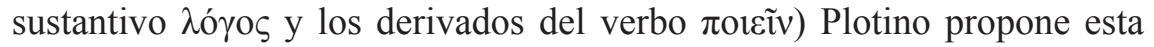
rica analogía, que por razones de claridad dividiremos en 4 subclases. Nos concentraremos sobre todo en las dos últimas, pues éstas se conectan más directamente con la doctrina de la justicia $\alpha \delta \rho \alpha \sigma \tau \varepsilon i ́ \alpha$.

1: Así como el drama, para ser atractivo artísticamente, necesita de toda clase de personajes, a saber, personajes heroicos y personajes bajos (verbigracia, criados o aldeanos "expresándose vulgarmente"), así también en la vida humana es menester que haya hombres virtuosos y hombres viciosos. Así como “el drama deja de ser bello ( elimina a los personajes vulgares, así la vida humana perdería su belleza si no existiese el contraste y el conflicto entre personas éticamente disímiles (En. III 2, 11, 15-16). Esta analogía, al igual que la ya mencionada de la

32 Cf. también En. III, 2, 6, 18.

33 Para el análisis de esta metáfora estoy en deuda con Ferretti (1999) y Longo (2001).

34 Kalligas (2014: 466). 
pintura o del canto, nos ayudaría a comprender que la maldad es en cierto modo un ingrediente irrenunciable en la conformación de un universo producido por una mente sabia.

2: Así como el cosmos es uno y está compuesto de partes contrarias y discordantes (el ejemplo más fácil de comprender es el de los contrarios físicos), así también la trama de una obra teatral es una y está compuesta de partes que entran en conflicto unas con otras (En. III 2, 16, 35-37). Esta analogía nos ayudaría a comprender que la unidad del universo no se ve menoscabada por el hecho de que dentro de su seno subsista la diversidad y el conflicto; por el contrario, la multiplicidad y rivalidad de las partes que conforman el todo están contenidas en la unidad de la trama de la obra. Así como el $\lambda$ ó $\gamma$ os, siendo uno, se diversifica y se multiplica en muchos $\lambda$ ó al informar, desde el alma del mundo, a las diferentes partes del mundo, así también la trama de una obra de teatro, siendo una, comprende en sí muchas tramas subordinadas y discordantes entre sí.

3: Así como en el teatro el autor del drama asigna los roles a actores que son de antemano (oṽov la divinidad providente le asigna a cada cual un papel de acuerdo a un mérito o demérito, de cuya responsabilidad él se mantiene ajeno. Así como no depende del autor de la obra el hecho de que existan buenos o malos actores, así la providencia no es responsable de la maldad o bondad de los hombres, sino que éstas dependen de sus elecciones (En. III 2, 17, 22-32).

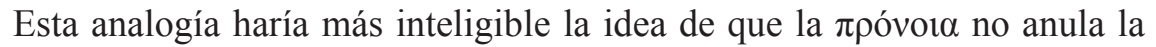
iniciativa de los agentes morales, sino que gobierna los destinos humanos contando con la participación activa de los mismos.

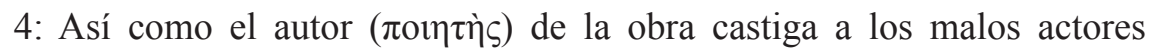
asignándoles peores papeles y premia a los buenos actores asignándoles mejores papeles, "actuando en esto como buen juez" (

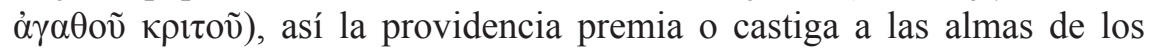
hombres asignándoles, de acuerdo a sus méritos, un nuevo cuerpo y unas nuevas circunstancias vitales que los pongan en la situación que merecen por su actuación anterior (En. III 2, 17, 19-21). Esta analogía debería hacernos comprender de qué modo la reencarnación de las almas está exigido en plan justo de la providencia (= el autor), cuyo dictamen es verdaderamente irrehuible. El autor sería quien pone las condiciones y las 
reglas de la obra, mientras que los actores ponen sus propios actos, por los cuales "reciben el castigo o la recompensa" (En. III 2, 17, 53).

Estas metáforas - y ciertamente las doctrinas que yacen detrás de ellas - plantean problemas difíciles de resolver. La Ley de Adrasteia, explicada a través de la cuarta analogía en nuestra clasificación, parece ser el caso más paradigmático, sobre todo por las implicancias éticas que podría conllevar. Si en realidad la mujer que es asaltada, golpeada y violada por criminales está sufriendo un justo castigo por sus crímenes, entonces su desgracia no debería inspirarnos compasión, pues como señala Aristóteles, esta emoción supone que quien sufre un mal, lo sufre inmerecidamente (cf. Retórica II 8, 1385b13-15). Además, si lo que dice Platón acerca del castigo es cierto y la desgracia que sufre en realidad se trata de un castigo, entonces no deberíamos compadecer a alguien que recibe un bien, a saber, la oportunidad de salir del error moral (Cf. Gorgias $476^{\mathrm{a}} \mathrm{ss}$ ). Si todo esto es cierto, la reacción de pasividad e indiferencia ante el espectáculo de un crimen horrible y evitable no sería éticamente reprochable. Esta conclusión se hace difícilmente sostenible, toda vez que nadie en su sano juicio consideraría que la conmiseración ante el mal ajeno - como, por ejemplo, la compasión (غ่̇ $\varepsilon$ os) que siente el filósofo luego de salir de la caverna, al acordarse de su antigua morada y de sus compañeros de cautiverio (cf. Rep. VII, 516C) - sea algo infundado y contrario a una ordenación ética del universo.

\section{A modo de conclusión}

Plotino se enfrenta a la permanente dificultad que enfrentan todas las teorías providencialistas, entendiendo 'providencialismo' la doctrina del gobierno total y no parcial del universo por parte de una divinidad buena y justa. En efecto, el onus probandi que toma sobre sí esta teoría consiste en defender la compatibilidad del gobierno completo del cosmos (incluyendo las acciones libres de los hombres) con la existencia innegable del mal físico y moral. Plotino reconoce que la constatación del mal es un argumento suficiente para poner en tela de duda el gobierno providencial del cosmos. Si negamos la providencia, las torpezas y vicios de los hombres

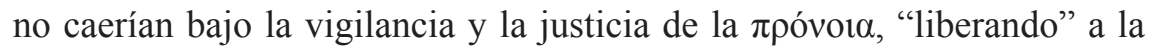
divinidad de esta tarea que pareciera serle indigna ${ }^{35}$ pero al mismo tiempo renunciando a la idea de una justicia universal que no deje ninguna acción

35 Cf. Epicuro, Carta a Meneceo 123ss. 
malvada (por ejemplo, las atrocidades cometidas por un tirano o el asesinato de una madre a manos de sus hijos) impune. Como hemos visto, Plotino toma el segundo camino, dando cuenta de la existencia de males prima facie inexplicables con la idea de Adrasteia, optando de este modo por una visión cósmica optimista, en la que la maldad es explicada con recurso a metáforas artísticas (una serie infinita de obras de teatro) que nos deberían

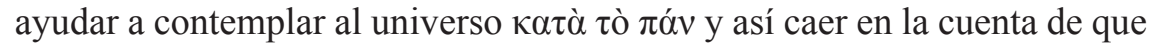
la maldad del universo sólo realza la belleza de este "gran drama". Si bien el lector difícilmente se verá convencido por esta metáfora, no puede negar que su fuerza plástica y su carácter sugerente la hacen justa merecedora de la fama que ha gozado en el imaginario humanista a través de la historia ${ }^{36}$.

\section{Bibliografía primaria}

AGUSTÍN DE HIPONA, De civitatedei.Ed. Dombart/Kalb. Corpus Christianorum Series Latina 42/43, Brepols 1995.

--------, De ordine. Ed. Green. Corpus Christianorum Series Latina 29, Brepols 1970.

ARISTÓTELES, Analytica Posteriora en Aristotle's Prior and Posterior Analytics. A revised text with introduction and commentary. Ed. Ross, Oxford 1949.

---------, De mundo en Aristotle: On Sophistical Refutations. On Coming-to-be and Passing Away.On the Cosmos. (Loeb Classical Library). Traducción Forster, E.S.; Furley, D.J. Harvard University Press, 1955.

BOECIO, De consolation philosophiae. Ed. Moreschini. Bibliotheca Scriptorum Graecorumet Romanorum Teubneriana, München/Leipzig, 2005.

CICERÓN, De natura deorum. rec. W. Ax/ O. Plasberg M. Tulli Ciceronis scripta quaemanuseruntomnia, fasciculus 45. Bibliotheca Scriptorum Graecorum et Romanorum Teubneriana, München/Leipzig 1998.

--------, De oratore, ed. K. F. Kumaniecki, M. Tulli Ciceronis scripta quaemanuseruntomnia, fasciculus 3. Bibliotheca Scriptorum Graecorum et Romanorum Teubneriana, München/Leipzig 1995.

DK = DIELS, H. / KRANZ, W. (EDS). Die Fragmente der Vorsokratiker (=DK). Berlín 1952.

36 Una primera versión de este artículo fue leída en el IV Congreso internacional de Estudios Griegos de 2014, organizado por el Centro de Estudios Griegos, Bizantinos y Neohelénicos "Fotios Malleros" de la Universidad de Chile. Agradezco las preguntas y comentarios de los allí participantes. Agradezco también especialmente las correcciones y sugerencias del Dr. José Antonio Giménez a una versión más avanzada de este artículo. 
ESQUILO, Prometeo Encadenado en Aeschyli Septem Quae Supersunt Tragoedias, Ed. Page, Oxford 1973.

EPICURO, Carta a Meneceo, en Epistulae Tres et Ratae Sententiae a Laertio Diogene Servatae: Accedit Gnomologium Epicureum Vaticanum. Bibliotheca scriptorum Graecorum et Romanorum Teubneriana. Peter von der Mühll (Ed.) 1998.

LONG, A./SEDLEY, D. (=LS). The Hellenistic Philosophers: Volume 2, Greek and Latin Texts with Notes and Bibliography. Cambridge 1989.

PLATÓN, Opera. Ed. J. Burnet, Oxford Classical Texts, Reimp.1961. (Traducciones usadas: Las Leyes: Francisco Lisi, Ed. Gredos, Madrid, 1999; Fedro: E. Lledó. Ed. Gredos, Madrid1986).

PLOTINO, Opera. Editiominor, 3 vols., Oxford University Press, 1964-1982. (Traducción castellana de J. Igal, Editorial Gredos, Madrid 1982).

PSEUDO- DIONISIO. De divinibusnominibus en Dionigi Areopagita, Tutte le Opere. Scazzoso P.; Bellini, E. (Eds.) Bompiani 2009.

SEXTO EMPÍRICO, Opera. Recensuit H. Mutschmann (3 Bde.); Lipsiae (Teubner, Leipzig) 1912-1954.

SVF $=$ Stoicorum Veterum Fragmenta. Ed. H. von Armin, Stuttgart 1978.

\section{Bibliografía secundaria}

BEUTLER, R; THEILER, W. (1956).Comentarios a Enéadas III, 2-3 en Plotin, Schriften, übers. von R. Hader, Neubearbeitung mit griechischen Lesetext und Anmerkungen. Tomo Vb, Felix Meiner, Hamburgo.

FERRETTI, S. (1999). "La metafora del mondo come teatro in Plotino. Enn. III 2" en Storia, filosofia e letteratura, a cura di Mario Reale,Napoli 1999, pp.77-96.

GRAF, F. (2003). Art. “Adrasteia” en Der Neue Pauly. Metzler. Tomo I, p. 129.

HERMANNI, F. (2002). Das Böse und die Theodizee. Eine philosophisch-theologische Grundlegung. Gütersloher Verlagshaus.

KAlligas, PAUL (2014). The Enneads of Plotinus. A Commentary.Vol 1. Translated by Elizabeth Key Fowden and Nicholas Pilavachi. Princeton University Press, 2014.

LONGO, A. (2001) "L'arte e il teatro per spigareil mondo: Plotino, Sulla Provvidenza, En. III, 2, 16-18” En Studiorientali e classici XLVIII, 3, pp. 503528.

MAYHEW, R. (2003) "The Theology of the Laws" en Bobonich, Ch. (Ed.) Cambridge Critial Guide to Plato's Laws. Cambridge.

MÜLLER, J. (2009) Art. "Seelenwanderung" en Horn, Ch. et al. (Eds.) Platon Handbuch. Metzler, pp.324-328. 
PARMA, CH. (1971).Pronoia und Providentia. Der Vorsehungsbegriff Plotins und Augustins. Leiden, 1971.

RICH, A. (1957) "Reincarnation in Plotinus". Mnemosyne, Fourth Series, Vol. 10, Fasc. 3 (1957), pp. 232-238.

SCHAEFER, CHRISTIAN (2000) "Das Dilemma der neuplatonischen Theodizee: Versuch einer Losung” en Archiv für Geschichte der Philosophie $(82,1)$, pp. 1-35.

SHARPLES, R.W. (1994) "Plato, Plotinus and Evil". Bulletin of the Institute of Classical Studies 39 pp. 171-181.

TONELLI, M. (2012) "La polémica acerca de la generación del mundo en el tiempo: Plotino frente a sus predecesores." En Synthesis, vol 19, 83-103, p. 83-103.

YUNIS, HARVEY (Ed.) (2011) Plato's Phaedrus. Cambridge University Press. Cambridge. 